\title{
Article \\ Occurrence and Persistency of Conduction Disturbances during Transcatheter Aortic Valve Implantation
}

\author{
Thomas T. Poels ${ }^{1, *}$, Elien B. Engels ${ }^{2}$, Suzanne Kats ${ }^{1}$, Leo Veenstra ${ }^{3}$, Vincent van Ommen ${ }^{3}$, Kevin Vernooy ${ }^{3}{ }^{0}$, \\ Jos G. Maessen ${ }^{1}\left(\mathbb{D}\right.$ and Frits W. Prinzen ${ }^{2}$ \\ 1 Department of Cardiothoracic Surgery, Maastricht University Medical Center, \\ P.O. Box 5800 Maastricht, The Netherlands; suzanne.kats@mumc.nl (S.K.); j.g.maessen@mumc.nl (J.G.M.) \\ 2 Department of Physiology, Faculty of Health, Medicine and Life Sciences, CARIM School for \\ Cardiovascular Diseases, P.O. Box 616 Maastricht, The Netherlands; elienengels@gmail.com (E.B.E.); \\ frits.prinzen@maastrichtuniversity.nl (F.W.P.) \\ 3 Department of Cardiology, Maastricht University Medical Center, P.O. Box 5800 Maastricht, The Netherlands; \\ 1.veenstra@mumc.nl (L.V.); v.van.ommen@mumc.nl (V.v.O.); kevin.vernooy@mumc.nl (K.V.) \\ * Correspondence: t.t.poels@amsterdamumc.nl
}

check for updates

Citation: Poels, T.T.; Engels, E.B.; Kats, S.; Veenstra, L.; van Ommen, V.; Vernooy, K.; Maessen, J.G.; Prinzen, F.W. Occurrence and Persistency of Conduction Disturbances during Transcatheter Aortic Valve Implantation. Medicina 2021, 57, 695. https://doi.org/10.3390/ medicina57070695

Academic Editor: Salvatore Mario Romano

Received: 28 June 2021

Accepted: 6 July 2021

Published: 7 July 2021

Publisher's Note: MDPI stays neutral with regard to jurisdictional claims in published maps and institutional affiliations.

Copyright: (c) 2021 by the authors. Licensee MDPI, Basel, Switzerland. This article is an open access article distributed under the terms and conditions of the Creative Commons Attribution (CC BY) license (https:/ / creativecommons.org/licenses/by/ $4.0 /)$.
Abstract: Background and Objectives: Conduction disturbances such as left bundle branch block (LBBB) and complete atrio-ventricular block (cAVB) are relatively frequent complications following trans-catheter aortic valve implantation (TAVI). We investigated the dynamics of these conduction blocks to further understand luxating factors and predictors for their persistency. Materials and Methods: We prospectively included 157 consecutive patients who underwent a TAVI procedure. Electrocardiograms (ECGs) were obtained at specific time points during the TAVI procedure and at follow-up until at least six months post-procedure. Results: Of the 106 patients with a narrow QRS complex (nQRS) before TAVI, 70\% developed LBBB; 28 (26.4\%) being classified as super-transient (ST-LBBB), $20(18.9 \%)$ as transient (T-LBBB) and $24(22.6 \%)$ as persistent (P-LBBB). Risk of LBBB was higher for self-expandable (SE) than for balloon-expandable (BE) prostheses and increased with larger implant depth. During the TAVI procedure conduction disturbances showed a dynamic behavior, as illustrated by alternating kinds of blocks in 18 cases. Most LBBBs developed during balloon aortic valvuloplasty (BAV) and at positioning and deployment of the TAVI prosthesis. The incidence of LBBB was not significantly different between patients who did and did not undergo BAV prior to TAVI implantation $(65.3 \%$ and $74.2 \%$, respectively $(p=0.494))$. Progression to cAVB was most frequent for patients with preexisting conduction abnormalities (5/34) patients) and in patients showing ST-LBBB (6/28). Conclusions: During the TAVI procedure, conduction disturbances showed a dynamic behavior with alternating types of block in 18 cases. After a dynamic period of often alternating types of block, most BBBs are reversible while one third persist. Patients with ST-LBBB are most prone to progressing into CAVB. The observation that the incidence of developing LBBB after TAVI is similar with and without BAV suggests that a subgroup of patients has a substrate to develop LBBB regardless of the procedure.

Keywords: transcatheter aortic valve implantation; left bundle branch block; electrocardiogram

\section{Introduction}

Transcatheter aortic valve implantation (TAVI) is a treatment option for patients with severe aortic valve stenosis who do not qualify for surgical aortic valve replacement (AVR) [1,2]. Despite its proven clinical benefits, conduction disturbances such as left bundle branch block (LBBB) remain one of the observed complications following TAVI. Previous studies reported that LBBB occurs in 7-65\% of the cases and that it persists in about one third of these cases [3-8]. Several studies showed that LBBB is associated with a higher mortality rate, presumably related to dyssynchrony-induced heart failure and development of atrioventricular (AV) block $[5,9,10]$. Luxating factors for the occurrence of 
LBBB, such as implantation depth, low ratio of annulus/balloon or annulus/prosthesis and the type of prosthesis, have been reported in post-procedural analyses [11]. Oedema and permanent compression by the prosthesis with resulting damage and/or ischemia $[8,11,12]$ have been suggested as potential causes for conduction disturbances following TAVI. Little prospective research has been performed for better understanding of the peri-operative luxating factors of conduction disturbances and predictors for persistency. In a small prospective research using Medtronic Corevalve prostheses, Nuis et al. showed that more than half of the LBBBs occur before prosthesis implantation, but long-term persistency was not investigated [8].

We sought to investigate the incidence, timing and dynamics of conduction disturbances in patients undergoing TAVI with emphasis on the development of LBBB to better understand the role of luxating factors.

\section{Materials and Methods}

\subsection{Study Population}

All consecutive patients who underwent a TAVI between April 2014 and June 2016 in the Maastricht University Medical Center were included in this study. Exclusion criteria were a pre-existing permanent pacemaker implantation (PPI) and implantation of a prior aortic valve prosthesis.

Our objective was to study at least 50 patients with a narrow QRS complex (nQRS) at baseline in order to analyze trends of conduction disturbances during TAVI. Taking into account patients with a wide QRS at baseline and to compensate for missing data and lost to follow-up, a total number of 150 patients was considered between April 2014 and June 2016. Patients were included from April 2014 to June 2016. Electrocardiographic data were prospectively collected in a central registry.

\subsection{Study Design}

Electrocardiograms (ECGs) were obtained preoperatively, postoperatively, before discharge and at follow-up after 6-12 months following TAVI.

Continuous 12-lead ECG (cECG) was recorded during key stages of the TAVI procedure as follows:

1. at baseline, within one minute prior to start of the procedure,

2. after advancing the soft guidewire through the aortic valve,

3. after placing the stiff wire through the aortic valve,

4. after positioning the valvuloplasty balloon through the aortic valve,

5. after performing the balloon aortic valvuloplasty (BAV),

6. after positioning the TAVI prosthesis in the native valve,

7. after deployment of the TAVI prosthesis and

8. at the end of the procedure after removal of all catheters.

All additional BAVs, both positioning and dilatation, following TAVI deployment, were also registered.

All ECGs were reviewed for ventricular conduction disturbances such as LBBB, right bundle branch block (RBBB), intraventricular conduction disturbance (IVCD) and complete atrioventricular block (cAVB). According to the established Strauss criteria, LBBB was defined as a QRS duration of $>140 \mathrm{~ms}$ (men) or $>130 \mathrm{~ms}$ (women), QS or rS in leads V1 and V2 and mid-QRS notching or slurring in 2 of leads V1, V2, V5, V6, I, and aVL [13]. RBBB was defined as a QRS complex $\geq 120$ ms with a triphasic QRS complex in V1 together with a dominant $S$ wave in leads I and V6 [14]. IVCD was defined as any other broad QRS complex $\geq 120$ not defined as a LBBB or RBBB.

Any new bundle branch block (BBB) on the $\mathrm{CECG}$ which had disappeared on the first postoperative ECG was defined as super-transient (ST). If a new BBB or CAVB was present postoperatively but disappeared at discharge or 6-12 months follow-up it was defined as transient (T). If the BBB or CAVB was still present on the follow-up ECG, it was considered persistent $(\mathrm{P})$. 
In order to study procedural related factors contributing to conduction disturbances, TAVI prostheses were divided into "balloon-expandable" (BE) and "self-expandable" (SE) prostheses, with BE prostheses being Edwards Sapien XT and -3 prostheses and SE prostheses comprising of Medtronic CoreValve, Medtronic Engager, Medtronic Evolut-R, St. Jude Medical Portico and Symetis Acurate.

\subsection{Statistical Analysis}

Categorical variables are presented as numbers, and proportions and binary logistic regression analysis were used to compare categorical variables with two categories and the $\chi^{2}$ test for categorical data with more than two categories.

For continuous variables, normality of distribution was assessed with the KolmogorovSmirnov test. Normal and skewed continuous variables are presented as means with standard deviation and medians with interquartile range, respectively. Differences between the groups were compared using the Kruskal-Wallis test, in case of a significant difference followed by a t-test while applying a Bonferroni correction for multiple comparisons. A two-side $p$-value $<0.05$ was considered significant.

All statistical analyses were performed using Statistical Package for Social Sciences, version 23 (IBM SPSS, Chicago, IL, USA).

\section{Results}

A total of 157 patients were reviewed, of whom 17 were excluded because they did not fulfil the eligibility criteria. Therefore, 140 patients qualified for analysis, of whom 106 had a narrow QRS (nQRS) complex before the TAVI procedure (Figure 1). The baseline and procedural characteristics of the 140 patients are shown in Table 1.

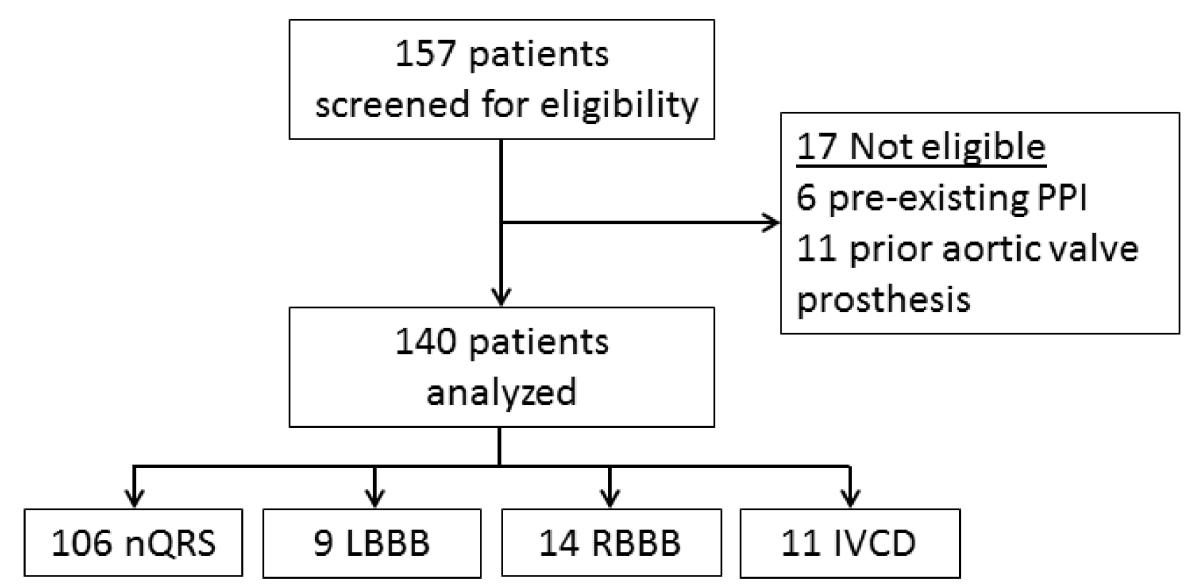

Figure 1. Study population. PPI: permanent pacemaker implantation; nQRS: narrow QRS; LBBB: left bundle branch block; RBBB: right bundle branch block; IVCD: intraventricular conduction disturbance.

Table 1. Baseline characteristics all patients and procedural factors.

\begin{tabular}{cc}
\hline & $n=\mathbf{1 4 0}$ \\
\hline Age (years) & $81[78-84]$ \\
Female $(n)$ & $75(53.6)$ \\
BMI $\left(\mathrm{kg} / \mathrm{m}^{2}\right)$ & $26.3[23.9-29.3]$ \\
Logistic EuroScore (\%) & $10.0[7.6-15.8]$ \\
EuroScore II (\%) & $2.7[1.6-4.1]$ \\
Additive Score (\%) & $8.0[7.0-10.0]$ \\
AF $(n)$ & $55(39.3)$ \\
NYHA $(n)$ & $3(2.1)$ \\
I & $40(28.6)$ \\
II & $92(65.7)$ \\
III & $5(3.6)$ \\
\hline
\end{tabular}


Table 1. Cont.

\begin{tabular}{|c|c|}
\hline & $n=140$ \\
\hline AMI $(n)$ & $24(17.1)$ \\
\hline PCI $(n)$ & $47(33.6)$ \\
\hline CABG $(n)$ & $24(17.1)$ \\
\hline CVA $(n)$ & $13(9.3)$ \\
\hline TIA $(n)$ & 15 (10.7) \\
\hline $\operatorname{PAD}(n)$ & $27(19.3)$ \\
\hline Carotid disease $(n)$ & $25(17.9)$ \\
\hline Diabetes $(n)$ & $52(37.1)$ \\
\hline Creatinin $(\mu \mathrm{mol} / \mathrm{L})$ & $91[77-114]$ \\
\hline $\operatorname{COPD}(n)$ & $21(15.0)$ \\
\hline Hypertension $(n)$ & $135(96.4)$ \\
\hline Hypercholesterolemia $(n)$ & $130(92.9)$ \\
\hline \multicolumn{2}{|l|}{ ECG } \\
\hline PR interval pre (ms) & 164 [133-190] \\
\hline QRS duration pre (ms) & $97[88-120]$ \\
\hline \multicolumn{2}{|l|}{ Echocardiogram } \\
\hline LVEF $(\%)$ & $58[50-64]$ \\
\hline Mean Gradient (mmHg) & $45.0 \pm 14.3$ \\
\hline Peak Gradient (mmHg) & $74.8 \pm 21.4$ \\
\hline Aortic Valve Area $\left(\mathrm{cm}^{2}\right)$ & $0.8[0.6-0.9]$ \\
\hline \multicolumn{2}{|l|}{ CT scan } \\
\hline Aortic annulus-short axis $(\mathrm{cm})$ & $2.2[2.1-2.4]$ \\
\hline Aortic annulus-Long axis (cm) & $2.8[2.6-2.9]$ \\
\hline Aortic annulus-Circumference (cm) & $8.0 \pm 0.9$ \\
\hline Aortic annulus-Area $\left(\mathrm{cm}^{2}\right)$ & $4.8 \pm 0.9$ \\
\hline Aortic annulus-Effective diameter $(\mathrm{cm})$ & $2.5[2.3-2.6]$ \\
\hline Aortic annulus-Perimeter derived diameter $(\mathrm{cm})$ & $2.5[2.4-2.7]$ \\
\hline \multicolumn{2}{|l|}{ Procedural factors } \\
\hline \multicolumn{2}{|l|}{ Access Route } \\
\hline Trans-femoral $(n)$ & $105(75.0)$ \\
\hline Trans-apical $(n)$ & $33(23.6)$ \\
\hline Trans-aortic $(n)$ & $2(1.4)$ \\
\hline \multicolumn{2}{|l|}{ Prosthesis type } \\
\hline Balloon-expandable $(n)$ & $117(83.6)$ \\
\hline Self-expandable $(n)$ & $23(16.4)$ \\
\hline \multicolumn{2}{|l|}{ Prosthesis size } \\
\hline $20 \mathrm{~mm}(n)$ & $3(2.1)$ \\
\hline $23 \mathrm{~mm}(n)$ & $35(25.0)$ \\
\hline $25 \mathrm{~mm}(n)$ & $3(2.1)$ \\
\hline $26 \mathrm{~mm}(n)$ & $66(47.1)$ \\
\hline $27 \mathrm{~mm}(n)$ & $1(0.7)$ \\
\hline $29 \mathrm{~mm}(n)$ & $32(22.9)$ \\
\hline Balloon aortic valvuloplasty $(n)$ & $99(70.7)$ \\
\hline \multicolumn{2}{|l|}{ Prosthesis depth } \\
\hline At Septum (mm) & $6.3[5.1-8.6]$ \\
\hline At Lateral wall (mm) & $5.7[4.2-7.3]$ \\
\hline PPI & $18(12.9)$ \\
\hline
\end{tabular}

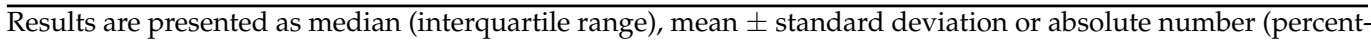
age). BMI: body mass index; AF: atrial fibrillation; NYHA: New York Heart Association; AMI: acute myocardial infarction; PCI: percutaneous coronary intervention; CABG: coronary artery bypass grafting; CVA: cerebrovascular accident; TIA: transient ischemic attack; PAD: peripheral arterial disease; COPD: chronic obstructive pulmonary disease; ECG: electrocardiogram; PRpre interval: PR interval preoperative; QRSpre duration: QRS duration preoperative; LVEF: left ventricular ejection fraction; CT: computerized tomography; PPI: permanent pacemaker implantation.

\subsection{Types of Conduction Disturbances}

Figure 2 shows the development of conduction disturbances throughout the TAVI procedure and follow-up. Among the 106 patients who started with a nQRS before TAVI 
(baseline), 72 (67.9\%) patients developed a conduction disturbance; $28(26.4 \%)$ patients developed a super-transient LBBB (ST-LBBB), 20 (18.9\%) a transient LBBB (T-LBBB) and 24 $(22.6 \%)$ a persistent LBBB (P-LBBB). Closer observation of the figure shows also that during the TAVI procedure many dynamic changes in conduction disturbances occurred, which were temporary in two-thirds of the cases. In eight nQRS patients a RBBB occurred, persisting in a third of them. Also, in 18 patients with a new LBBB, a temporary RBBB occurred (example shown in Figure 3, with two patients also having a temporary cAVB). Thirteen patients received a PPI at follow-up indicating progression of conduction disturbance. This was especially prominent in ST-LBBB patients $(6 / 28)$ and P-LBBB patients $(4 / 24)$.

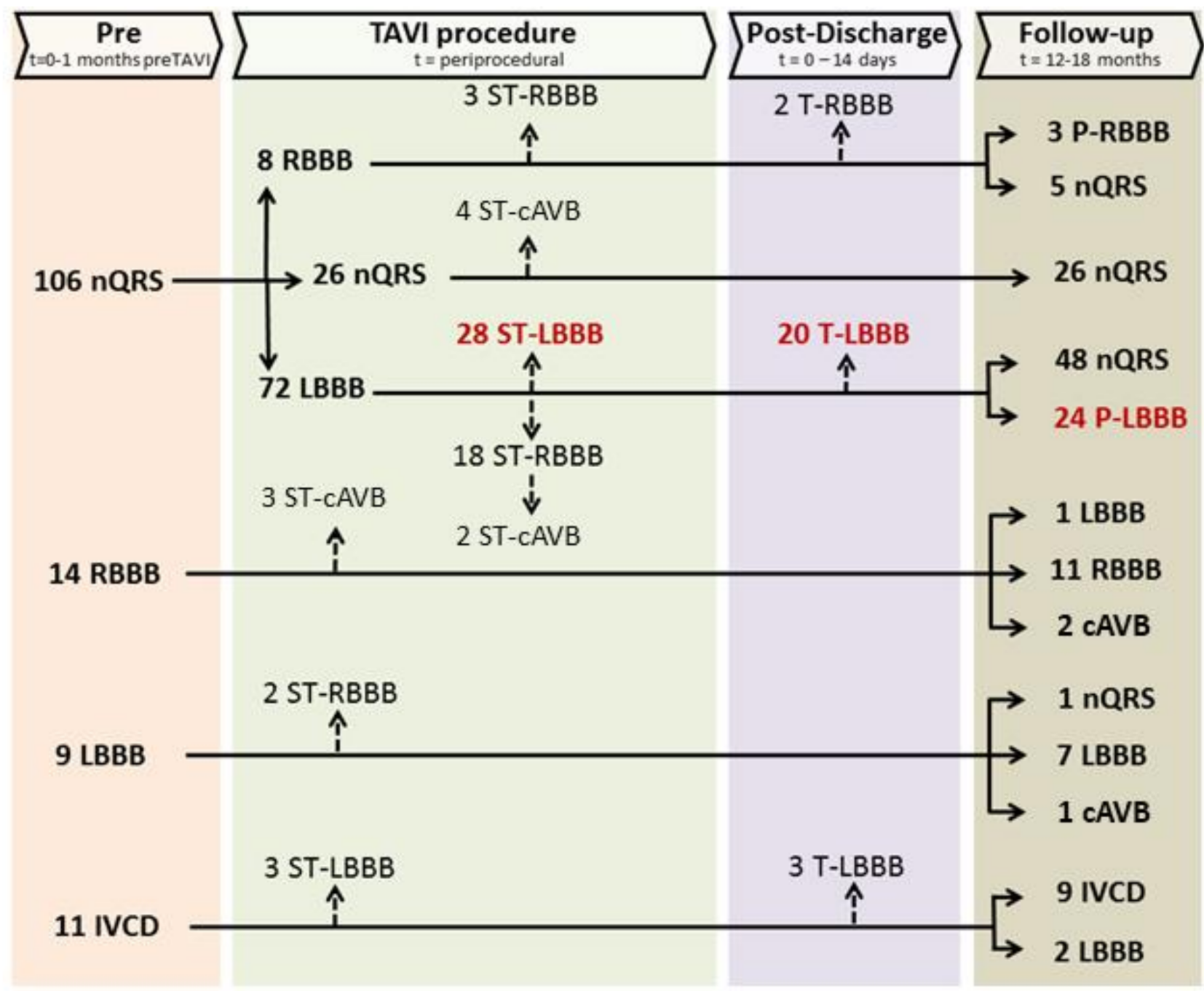

Figure 2. Types and dynamics of conduction disturbances in TAVI. Arrows within a 'time-block' show the dynamic nature of block development. Super-transient conduction disturbance is defined as any conduction disturbance present on the continuous electrocardiogram (ECG) during the transcatheter aortic valve implantation (TAVI) procedure which was not present on the first postoperative ECG. Transient conduction disturbance is defined as any new conduction disturbance present postoperative but disappeared at discharge or follow-up. Persistent conduction disturbance is defined as any new conduction disturbance present on the follow-up ECG. nQRS: narrow QRS; LBBB: left bundle branch block; RBBB: right bundle branch block; IVCD: intraventricular conduction disturbance; cAVB: third degree atrioventricular block; ST-: super transient-; T-: transient-; P-: persistent-. 


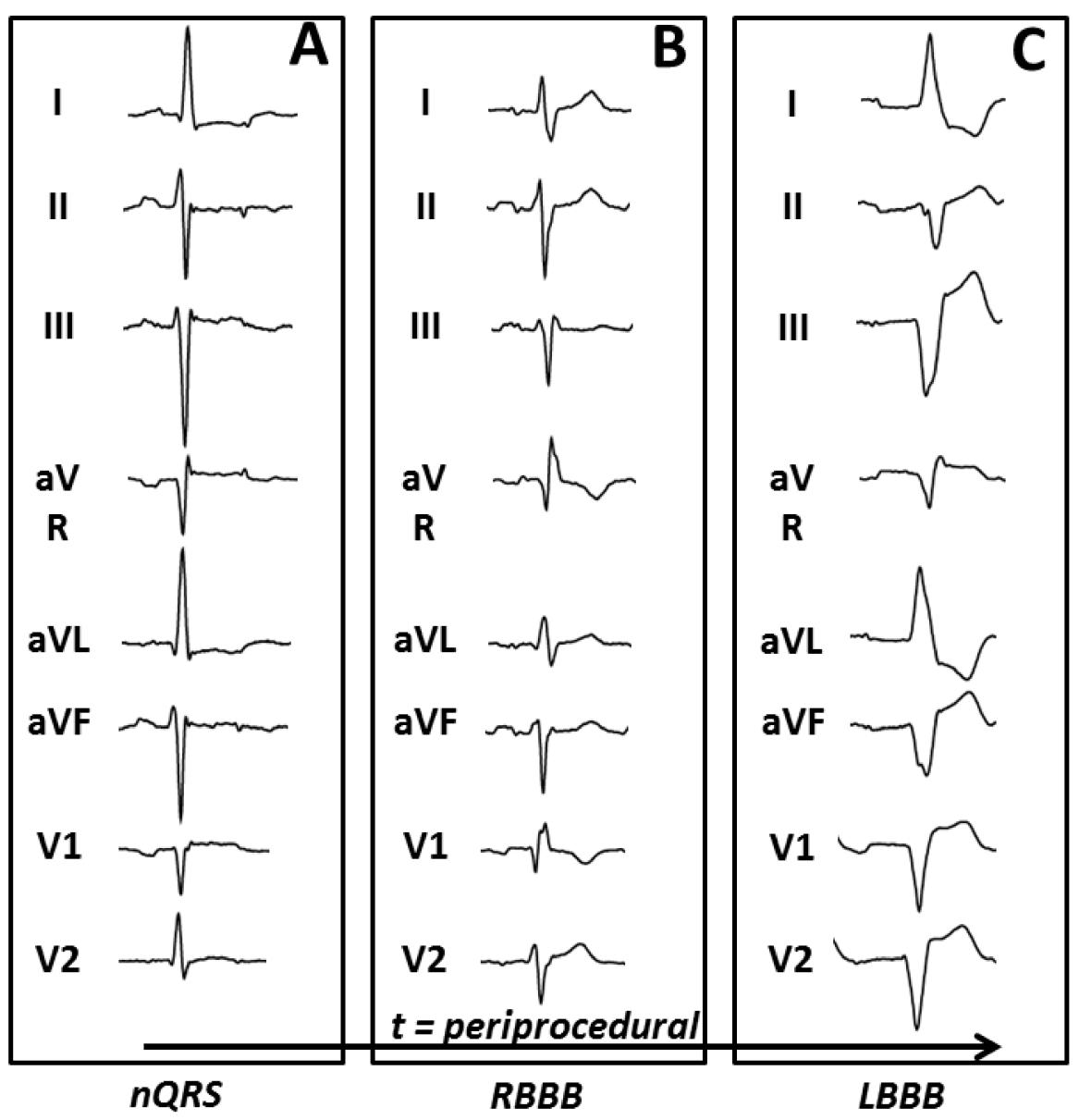

Figure 3. ECG example in a single study patient undergoing TAVI: ECG examples of a single patient with a baseline $\mathrm{QRS}$ (A), converting periprocedural at insertion of the stiff wire into RBBB (B) and later switching to LBBB with PR prolongation after deployment of the TAVI (C). ECG: electrocardiogram; nQRS: narrow QRS complex; RBBB: right bundle branch block; LBBB: left bundle branch block.

Five out of the fourteen patients with a RBBB at baseline developed a CAVB, which was persistent in two patients and required a PPI. In the nine patients with a LBBB at baseline, two patients developed a ST-RBBB, one patient changed into nQRS and one patient developed a cAVB. In the 11 patients with an IVCD before TAVI, 8 developed a LBBB, being persistent in 2 patients. These alternating types of block show severe disturbance of the distal conduction pathways during the TAVI procedure.

\subsection{Baseline and Procedural Characteristics}

Table 2 shows baseline characteristics of the nQRS, ST-LBBB, T-LBBB and P-LBBB subgroups and indicates that a history of PCI and no-hypercholesterolemia significantly increased the chance of developing a P-LBBB. There were no differences in echocardiographic and CT-scan parameters between the subgroups. 
Table 2. Baseline characteristics of LBBB groups.

\begin{tabular}{|c|c|c|c|c|c|}
\hline Baseline Characteristics & nQRS $(n=34)$ & ST-LBBB $(n=28)$ & T-LBBB $(n=20)$ & P-LBBB $(n=24)$ & $p$ Value \\
\hline Age (years) & $80.00[74.75-85.00]$ & 80.00 [76.50-84.00] & $81.50[78.00-83.00]$ & $83.00[77.75-85.00]$ & 0.549 \\
\hline Female $(n)$ & $21(61.8)$ & $11(39.3)$ & $13(65.0)$ & $17(70.8)$ & 0.100 \\
\hline $\mathrm{BMI}\left(\mathrm{kg} / \mathrm{m}^{2}\right)$ & $26.17[23.26-29.32]$ & $26.47[23.08-30.96]$ & $26.38[24.10-31.70]$ & $26.12[24.05-27.66]$ & 0.795 \\
\hline Logistic EuroScore (\%) & $10.90[7.69-16.66]$ & $9.02[6.89-11.74]$ & $9.33[6.86-11.24]$ & $11.93[8.28-19.39]$ & 0.187 \\
\hline EuroScore II (\%) & 3.01 [1.95-3.95] & $2.52[1.56-3.36]$ & $2.07[1.55-3.45]$ & $2.82[1.62-5.76]$ & 0.133 \\
\hline Additive Score (\%) & $9.00[7.00-10.00]$ & $8.00[7.00-8.75]$ & $8.00[7.00-8.00]$ & $8.50[8.00-10.00]$ & 0.187 \\
\hline $\operatorname{AF}(n)$ & $16(47.1)$ & $11(39.3)$ & $5(25.0)$ & $9(37.5)$ & 0.457 \\
\hline NYHA $(n)$ & & & & & 0.050 \\
\hline I & $0(0.0)$ & $0(0.0)$ & $0(0.0)$ & $3(12.5)$ & \\
\hline II & $9(26.5)$ & $6(21.4)$ & $8(40.0)$ & $5(20.8)$ & \\
\hline III & $24(70.6)$ & $22(78.6)$ & $10(50.0)$ & $15(62.5)$ & \\
\hline IV & $1(2.9)$ & $0(0.0)$ & $2(10.0)$ & $1(41.7)$ & \\
\hline $\operatorname{AMI}(n)$ & $5(14.7)$ & $5(17.9)$ & $1(5.0)$ & $2(8.3)$ & 0.507 \\
\hline PCI $(n)$ & $9(26.5)$ & $11(39.3)$ & $2(10.0)$ & $13(54.2)$ & 0.013 \\
\hline CABG $(n)$ & $7(20.6)$ & $2(7.1)$ & $1(5.0)$ & $5(20.8)$ & 0.208 \\
\hline $\operatorname{CVA}(n)$ & $5(14.7)$ & $3(10.7)$ & $1(5.0)$ & $2(8.3)$ & 0.701 \\
\hline TIA $(n)$ & $5(14.7)$ & $3(10.7)$ & $1(5.0)$ & $3(12.5)$ & 0.746 \\
\hline $\operatorname{PAD}(n)$ & $9(26.5)$ & $7(25.0)$ & $3(15.0)$ & $4(16.7)$ & 0.677 \\
\hline Carotid disease $(n)$ & $8(23.5)$ & $5(17.9)$ & $0(0.0)$ & $6(25.0)$ & 0.116 \\
\hline Diabetes $(n)$ & $12(35.3)$ & $10(35.7)$ & $9(45.0)$ & $11(45.8)$ & 0.783 \\
\hline Creatinin $(\mu \mathrm{mol} / \mathrm{L})$ & $\begin{array}{c}88.50 \\
{[77.75-115.50]}\end{array}$ & $\begin{array}{c}91.50 \\
{[73.50-109.50]}\end{array}$ & $\begin{array}{c}91.50 \\
{[77.25-109.00]}\end{array}$ & $\begin{array}{c}91.50 \\
{[77.25-114.25]}\end{array}$ & 0.298 \\
\hline $\operatorname{COPD}(n)$ & $6(17.6)$ & $6(17.6)$ & $4(20.0)$ & $4(16.7)$ & 0.970 \\
\hline Hypertension $(n)$ & $33(97.1)$ & $28(100.0)$ & $19(95.0)$ & $23(95.8)$ & 0.725 \\
\hline Hypercholesterolemia $(n)$ & $34(100.0)$ & $27(96.4)$ & $19(95.0)$ & $19(79.2)$ & 0.013 \\
\hline \multicolumn{6}{|l|}{ ECG } \\
\hline PR interval pre (ms) & $\begin{array}{c}96.00 \\
{[88.00-105.00]}\end{array}$ & $\begin{array}{c}91.00 \\
{[80.50-100.00]}\end{array}$ & $89.00[86.00-94.00]$ & $\begin{array}{c}90.00 \\
{[86.00-100.00]}\end{array}$ & 0.202 \\
\hline QRS duration pre (ms) & $\begin{array}{c}169.00 \\
{[153.0-191.0]}\end{array}$ & $\begin{array}{c}177.00 \\
{[159.00-190.50]}\end{array}$ & $\begin{array}{c}175.00 \\
{[159.00-190.00]}\end{array}$ & $\begin{array}{c}172.00 \\
{[143.00-195.00]}\end{array}$ & 0.675 \\
\hline \multicolumn{6}{|l|}{ Echocardiogram } \\
\hline LVEF $(\%)$ & $58.00[49.00-65.00]$ & $59.50[50.75-63.00]$ & $59.50[55.00-65.00]$ & $58.50[57.00-66.75]$ & 0.814 \\
\hline MG (mmHg) & $40.00(15.48)$ & $51.00(17.56)$ & $45.00(10.96)$ & $44.00(14.00)$ & 0.874 \\
\hline PG $(\mathrm{mmHg})$ & $74.50(22.86)$ & $77.00(24.71)$ & $75.00(16.10)$ & $70.50(21.79)$ & 0.870 \\
\hline $\operatorname{AVA}\left(\mathrm{cm}^{2}\right)$ & $0.80[0.60-1.00]$ & $0.80[0.60-0.90]$ & $0.70[0.55-1.00]$ & $0.70[0.50-0.89]$ & 0.538 \\
\hline \multicolumn{6}{|l|}{ CT scan } \\
\hline AN-short axis (cm) & $2.20[2.08-2.40]$ & $2.20[2.04-2.30]$ & $2.25[2.03-2.40]$ & $2.10[2.00-2.55]$ & 0.727 \\
\hline AN-Long axis (cm) & $2.70[2.50-2.90]$ & $2.80[2.60-3.02]$ & $2.70[2.60-2.89]$ & $2.75[2.50-2.90]$ & 0.381 \\
\hline AN-Circumference $(\mathrm{cm})$ & $7.80(0.87)$ & $8.00(0.75)$ & $7.85(1.31)$ & $7.90(0.69)$ & 0.494 \\
\hline AN-Area $\left(\mathrm{cm}^{2}\right)$ & $4.70(1.06)$ & $4.71(0.95)$ & $4.60(0.74)$ & $4.70(0.79)$ & 0.883 \\
\hline AN-Effective diameter $(\mathrm{cm})$ & $2.50[2.30-2.53]$ & $2.45[2.25-2.60]$ & $2.43[2.28-2.63]$ & $2.50[2.30-2.63]$ & 0.951 \\
\hline $\begin{array}{l}\text { AN-Perimeter derived } \\
\text { diameter }(\mathrm{cm})\end{array}$ & $2.48[2.30-2.64]$ & $2.50[2.40-2.73]$ & $2.60[2.50-2.75]$ & $2.55[2.33-2.68]$ & 0.499 \\
\hline
\end{tabular}

Results are presented as median (interquartile range), mean \pm standard deviation or absolute number (percentage). BMI: body mass index; AF: atrial fibrillation; NYHA: New York Heart Association; AMI: acute myocardial infarction; PCI: percutaneous coronary intervention; CABG: coronary artery bypass grafting; CVA: cerebrovascular accident; TIA: transient ischemic attack; PAD: peripheral arterial disease; COPD: chronic obstructive pulmonary disease; ECG: electrocardiogram; PRpre interval: PR interval preoperative; QRSpre duration: QRS duration preoperative; LVEF: left ventricular ejection fraction; MG: mean gradient; PG: peak gradient; AVA: aortic valve area; CT: computerized tomography; AN: aortic annulus.

With respect to procedural factors (Table 3), SE prostheses were nearly three times more likely to develop a P-LBBB than BE prostheses $(p<0.05)$. Implantation depth was approximately $2 \mathrm{~mm}$ more in P-LBBB patients than in the other three sub-groups, $p=0.12$ (Table 3). 
Table 3. Procedural factors for all LBBB groups.

\begin{tabular}{|c|c|c|c|c|c|}
\hline Procedural Factors & nQRS $(n=34)$ & ST-LBBB $(n=28)$ & T-LBBB $(n=20)$ & P-LBBB $(n=24)$ & $p$ Value \\
\hline Access Route & & & & & 0.124 \\
\hline $\mathrm{TF}(n=79)$ & $20(25.3)$ & $22(27.8)$ & $17(21.5)$ & $20(25.3)$ & \\
\hline TA $(n=26)$ & $14(53.8)$ & $5(19.2)$ & $3(11.5)$ & $4(15.4)$ & \\
\hline $\mathrm{TAO}(n=1)$ & $0(0.0)$ & $1(3.6)$ & $0(0.0)$ & $0(0.0)$ & \\
\hline Prosthesis type ${ }^{*}$ & & & & & 0.014 \\
\hline Balloon-expandable $(n=87)$ & $29(33.3)$ & $27(31.0)$ & $16(18.4)$ & $15(17.2)$ & \\
\hline Self-expandable $(n=19)$ & $5(26.3)$ & $1(5.3)$ & $4(21.1)$ & $9(47.4)$ & \\
\hline Prosthesis size * & & & & & 0.181 \\
\hline 20 & $1(100.0)$ & $0(0.0)$ & $0(0.0)$ & $0(0.0)$ & \\
\hline 23 & $13(41.9)$ & $7(22.6)$ & $3(9.7)$ & $8(25.8)$ & \\
\hline 25 & $0(0.0)$ & $1(100.0)$ & $0(0.0)$ & $0(0.0)$ & \\
\hline 26 & $15(30.6)$ & $15(30.6)$ & $11(22.4)$ & $8(16.3)$ & \\
\hline 27 & $0(0.0)$ & $0(0.0)$ & $0(0.0)$ & $1(100.0)$ & \\
\hline 29 & $5(21.7)$ & $5(21.7)$ & $6(26.1)$ & $7(30.4)$ & \\
\hline $\begin{array}{l}\text { Balloon aortic valvuloplasty } \\
\qquad(n=75)\end{array}$ & $26(34.7)$ & $18(24.0)$ & $16(21.3)$ & $15(20.0)$ & 0.446 \\
\hline \multicolumn{6}{|l|}{ Prosthesis depth } \\
\hline At Septum (mm) & 6.14 [5.09-8.13] & $6.18[4.63-8.32]$ & $6.32[4.83-7.18]$ & 8.34 [5.67-10.72] & 0.122 \\
\hline At Lateral wall (mm) & $5.62[4.05-7.09]$ & $5.79[4.33-6.85]$ & $4.83[4.40-7.61]$ & 6.42 [3.79-9.61] & 0.556 \\
\hline PPI $(n=13)$ & $1(7.7)$ & $6(46.2)$ & $2(15.4)$ & $4(30.8)$ & 0.144 \\
\hline
\end{tabular}

${ }^{*}$ Percentages were calculated per row. Results are presented as absolute number (percentage) or (in case of prosthesis depth) as median (interquartile range). TF: transfemoral; TA: trans-apical; TAO: trans-aortic; PPI: permanent pacemaker implantation.

\subsection{Time of Onset and Persistence of New LBBB and Cavb}

Figure $4 \mathrm{~A}, \mathrm{~B}$ shows that no new LBBB was observed from baseline up to advancement of the guidewire through the aortic valve. In the patients where BAV was used (SE 8/19, BE 67/87), most LBBBs developed at BAV and at positioning and deployment of the TAVI prosthesis. The 31 patients who did not undergo BAV prior to TAVI implantation did not develop significantly less LBBBs during the entire procedure, $(74.2 \%$ versus $65.3 \%$ for the noBAV and BAV groups, respectively; $(p=0.49)$ (Table 4$)$ ). This was due to a higher percentage of new LBBB acquired during positioning of the TAVI prosthesis in the noBAV compared to that in the BAV group (32.3\% versus $13.3 \%$, respectively (Figure $4 A, B)$ ). Furthermore, the noBAV and BAV groups did not significantly differ with respect to the development of ST-LBBB (32.3\% vs. $24.0 \%(p=0.47))$, T-LBBB $(12.9 \%$ vs. $21.3 \%(p=0.42))$ and P-LBBB $(29.0 \%$ vs. $20.0 \%(p=0.32))$, respectively (Figure 4$)$. Also, the persistency of LBBB was independent of the moment of development of the LBBB in patients with BAV; in patients without BAV most P-LBBB developed at TAVI deployment (Figure 4A,B). 
(A) All patients with balloon aortic valvuloplasty, total $n=75$, LBBB $n=49$

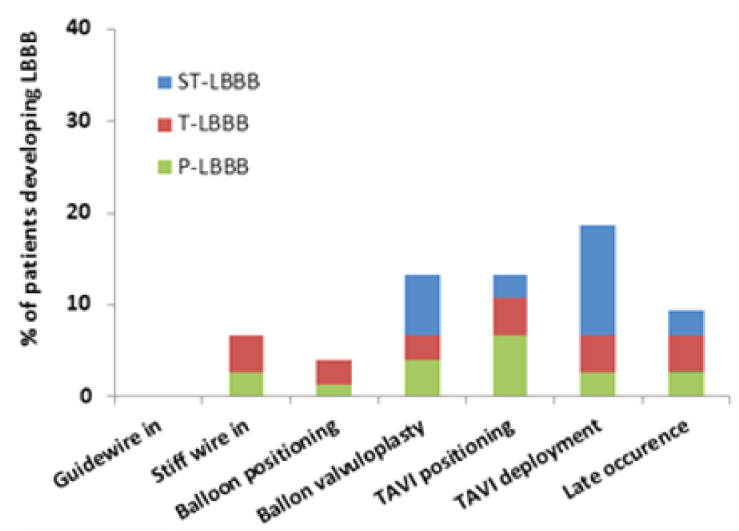

(C) All patients with balloon expandable prosthesis, total $n=87$, LBBB $n=58$

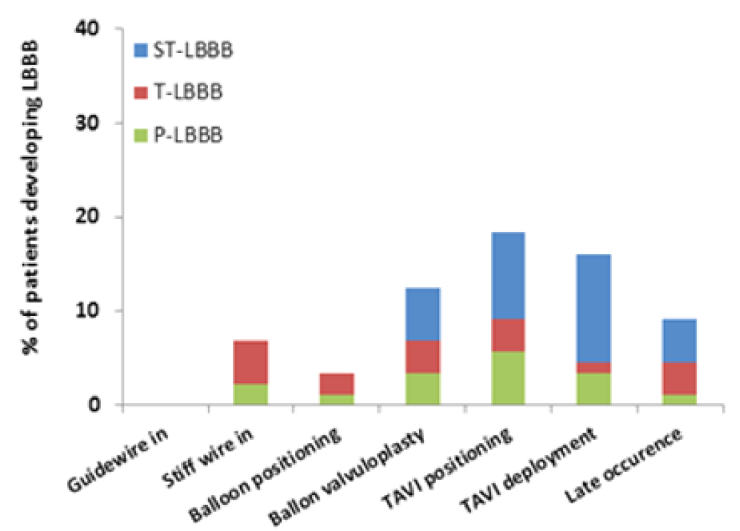

(B) All patients without balloon aortic valvuloplasty, total $n=31$, LBBB $n=23$

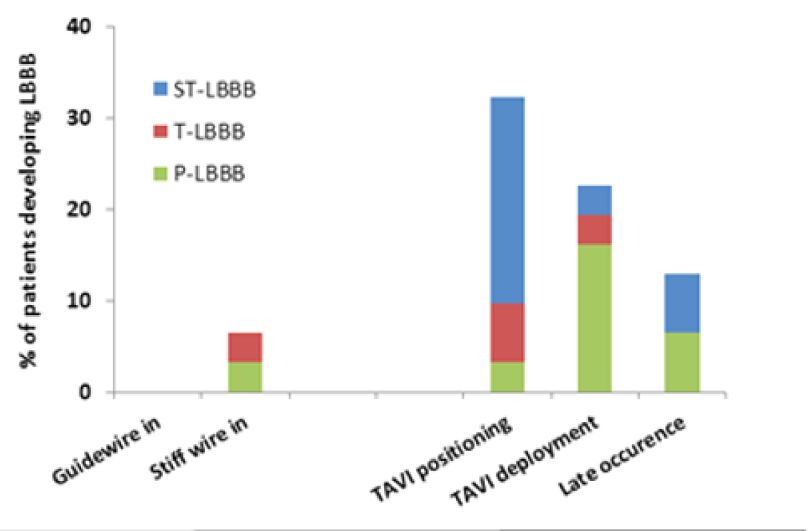

(D) All patients with self expandable prosthesis, total $n=19$, LBBB $n=14$

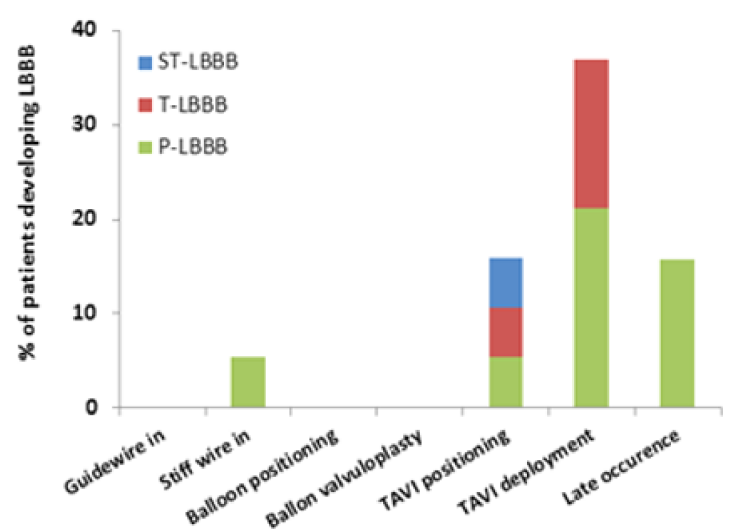

Figure 4. Distribution of first occurrence of new LBBB (in percentages) in patients with (A) and without BAV (B) and distribution of first occurrence of new LBBB (in percentages) in patients with balloon-expandable (C) and self-expandable valves (D). Distribution of first occurrence of new LBBB during the transcatheter aortic valve implantation (TAVI) procedure for patients who developed any LBBB for (A) all patients who had a balloon aortic valvuloplasty (BAV) prior to TAVI prosthesis implantation $(n=75)$ and $(\mathbf{B})$ all patients who did not have such a BAV $(n=31)$. Distribution of first occurrence of new LBBB during the transcatheter aortic valve implantation (TAVI) procedure for patients who developed any LBBB for (C) all patients with a balloon-expandable prosthesis $(n=87)$ and $(\mathbf{D})$ all patients with a self-expandable prosthesis $(n=19)$. LBBB: left bundle branch block; ST-: super transient-; T-: transient-; P-: persistent.

Table 4. Risk of development of LBBB in procedures with and without balloon aortic valvuloplasty.

\begin{tabular}{cccc}
\hline & BAV $(\boldsymbol{n}=\mathbf{7 5})$ & noBAV $(\boldsymbol{n}=\mathbf{3 1})$ & $\boldsymbol{p}$-Value \\
\hline nQRS $(n)$ & $26(34.7)$ & $8(25.8)$ & 0.49 \\
ST-LBBB $(n)$ & $18(24.0)$ & $10(32.3)$ & 0.47 \\
T-LBBB $(n)$ & $16(21.3)$ & $4(12.9)$ & 0.42 \\
P-LBBB $(n)$ & $15(20.0)$ & $9(29.0)$ & 0.32
\end{tabular}

Results are presented as absolute number (percentage). LBBB: left bundle branch block; ST-: super transient-; T-: transient-; P-: persistent; nQRS: narrow QRS complex; BAV: balloon aortic valvuloplasty; noBAV: no balloon aortic valvuloplasty.

Patients with a SE prosthesis have almost twice the risk of developing a new LBBB during TAVI deployment and at late occurrence compared to BE prostheses, with most being persistent (Figure 4C,D).

Approximately 15\% of all new LBBBs occurred 'late', defined as after deployment of the TAVI prosthesis but before the end of the procedure. The patients with a SE prosthesis seemed to have almost double the risk of developing such a late conduction disturbance (4/19) compared to BE prostheses (11/87) (Figure 4C,D). 
All cAVBs occurred at positioning or deployment of the BAV or TAVI prosthesis. Four PPI occurred before discharge and nine at follow-up.

\section{Discussion}

The present study shows the high frequency and dynamic nature of conduction disturbances developing during TAVI. In the entire cohort only $32 \%$ of patients did not develop any conduction block during the TAVI procedure, while $23 \%$ developed a persistent left bundle branch block and 3\% a persistent right bundle branch block. The remaining $45 \%$ developed various forms of transient blocks. The study shows the dynamicity of development of conduction disturbances by the frequent switching between LBBB, RBBB, CAVB and $\mathrm{nQRS}$ during the procedure. Importantly, particular P-LBBB and ST-LBBB patients progressed into AVB, requiring PPI. Furthermore, the percentage of LBBB is similar in patients with and without $\mathrm{BAV}$, suggesting that the development of $\mathrm{BBB}$ is (almost) inevitable in a subpopulation of patients following TAVI procedure. This may be explained by the fact that we described that the effective distance between the aortic valve and conduction system (EDACS) predicts LBBB, which is a patient-specific anatomy [15].

\subsection{The Dynamics of TAVI-Induced Conduction Blocks}

The continuous ECG monitoring in the present study has elucidated the dynamics of conduction disturbances during the TAVI procedure, as evidenced by any conduction abnormality in $\sim 70 \%$ of patients and even alternating blocks within the same patient. Besides the previously reported T-LBBB and P-LBBB [16], we now demonstrate that a quarter of all patients develop a ST-LBBB during the TAVI procedure.

Striking was also the occurrence of new RBBB, with or without alternation to LBBB or cAVB. The occurrence of RBBB has been previously reported but with very low incidence [17]. The higher incidence in our study can be explained by also including ST-RBBBs. Because the right bundle branch itself is not close to the aortic valve, direct contact of the prosthesis and the right bundle branch is unlikely. However, it is known that within the His bundle the fibers of the right (RBB) and left bundle branch (LBB) are already separated $[18,19]$. Therefore, TAVI-induced RBBB may be related to the damage caused by the prosthesis to the area of the His bundle containing RBB fibers. The alternation between RBBB, LBBB and CAVB may be explained by minute motion of prosthesis parts near the proximal rapid conduction system. Considering that the thickness of the bundle of His is only a few millimeters, small changes following contact with the prosthesis can affect one or both branches (inducing LBBB or RBBB) with potential for CAVB.

Almost a quarter of all patients developed a P-LBBB with SE prostheses being particularly prone to persistency. Follow-up of one year showed that $16.7 \%(4 / 24)$ of patients with P-LBBB required a PPI at follow-up. Interestingly, an even larger percentage of patients with a ST-LBBB $(21.4 \%(6 / 28))$ required a PPI, showing that this subgroup should receive more intensive follow-up.

\subsection{Potential Mechanisms of Conduction Disturbances Induced by TAVI}

There is little evidence concerning the exact mechanism for the development of conduction blocks following TAVI. Apparently, no animal studies are available to formulate suitable hypotheses. Our observations may help shed some lights on potential causes for these events.

Most conduction blocks developed during the actual TAVI with resolution in the majority of cases by the end of the procedure. Only a minority of blocks developed after the procedure or even days later.

The rapid development of the blocks may be caused by direct physical damage or compression-induced ischemic damage to the cells of the conduction system or interstitial edema. Permanent mechanical or ischemic damage cannot recover within hours, because myocytes, which are responsible for impulse propagation, do not divide. On the other hand, temporary ischemia may be caused by initial myocardial compression and subsequent 
settling of the prosthesis in the aortic root. Alternatively, damage may have caused swelling of the extracellular space, which results in disruption of the gap junctions [20-22] and may resolve within minutes to hours. The few slower developing conduction blocks may be elicited by gradually increasing ischemia and/or inflammatory and degenerative processes.

\subsection{Luxating Factors of New LBBB and Predictors for Persistency}

The observation that the total number of TAVI-induced LBBBs in BAV and noBAV patients was similar, suggests that there are patients who are susceptible to any manipulation at the aortic annulus, regardless of whether this is from BAV or TAVI positioning. This suggests an anatomical substrate for TAVI-induced conduction blocks. Such substrate may be related to specific anatomy of the membranous septum [23], pre-existent conduction delays as demonstrated in electrophysiology studies with an increased HV-interval [24,25] or the presence of calcifications and other pathological disturbances [11]. Better recognition of such a substrate could reduce the number of TAVI-induced conduction disturbances and thereby the outcome of the procedure.

Besides the presence of a patient-specific substrate, Table 3 shows that almost half of all SE prostheses produced a P-LBBB, indicating also prosthesis-specific luxating factors. Deeper implantation of the prosthesis into the left ventricular outflow tract can explain why these SE prostheses are at risk of persistent conduction disturbances [3,6,26,27]. Other investigators have also proposed that the self-expanding frame of such prostheses could induce, besides the reported late conduction blocks, persistent conduction blocks [16,28,29].

The observation that most LBBBs and cAVBs were luxated at BAV and at positioning and deployment of the TAVI prosthesis corresponds with the findings of Nuis et al. [8]. In addition, the proportion of temporary versus permanent LBBB appears similar in our BAV group to that in their study. These investigators studied 65 patients who received BAV prior to SE prosthesis implantation. The difference between this study and ours is that most of our patients received BE prostheses. The difference in prosthesis types used may also explain why the percentage of new LBBBs (excluding ST-LBBB) after BAV in our study are only a quarter of those reported by Nuis et al. [8] ( 10\% compared to $40 \%)$, as the BE prostheses create 2-3 times less conduction disturbances [30].

\subsection{Study Limitations}

Because of the observational design, our study could be hampered by information and selection bias. Still, all data were prospectively collected from a consecutive series of patients and entered in a central database with established definitions.

As patients undergoing TAVI are increasingly younger and fitter, not only the procedure itself with associated conduction disturbances are important to assess but also preventive (traditional) cardiovascular risk factors such as smoking on TAVI outcomes will become more important and thus advisable for future research [31,32].

\subsection{Clinical Implications}

Continuous measurement of the ECG during TAVI is useful because important conduction abnormalities such as ST-LBBB can be detected. ST-LBBB may be a warning sign for progression to $\mathrm{CAVB}$ at follow-up, thus warranting adequate rhythm monitoring postoperative and in the outpatient care setting. An implantable loop-recorder could be a good interim solution until further data are available for selecting the correct patients who require a pacemaker to prevent them from cAVB-caused bradycardia.

\section{Conclusions}

This study shows the high frequency of conduction blocks developing during TAVI and their dynamic nature, with most blocks disappearing within hours. The alternating pattern between $\mathrm{LBBB}, \mathrm{RBBB}$ and progression to CAVB suggests involvement of the His bundle in the pathophysiology. 
Important novel observations in this study were that the use of BAV does not influence the occurrence of LBBB, but that the use of SE prostheses does. Moreover, ST-LBBB is not innocent, because it has a high risk of developing $\mathrm{CAVB}$, therefore, perhaps indicating the need for PPI.

Author Contributions: Conceptualization, T.T.P. and F.W.P.; methodology, T.T.P. and F.W.P.; formal analysis, T.T.P. and F.W.P.; investigation, T.T.P., E.B.E. and F.W.P.; resources, S.K., L.V., V.v.O. and K.V.; data curation, T.T.P.; writing—original draft preparation, T.T.P. and F.W.P.; writing-review and editing, T.T.P., F.W.P. and J.G.M. All authors have read and agreed to the published version of the manuscript.

Funding: This research received no external funding.

Institutional Review Board Statement: The study was conducted according to the guidelines of the Declaration of Helsinki. Ethical review and approval were waived for this study, due to the retrospective setup of the study.

Data Availability Statement: Not applicable.

Conflicts of Interest: The authors declare no conflict of interest.

\section{References}

1. Rodés-Cabau, J.; Webb, J.G.; Cheung, A.; Ye, J.; Dumont, E.; Feindel, C.M.; Osten, M.; Natarajan, M.K.; Velianou, J.L.; Martucci, G.; et al. Transcatheter aortic valve implantation for the treatment of severe symptomatic aortic stenosis in patients at very high or prohibitive surgical risk: Acute and late outcomes of the multicenter Canadian experience. J Am. Coll. Cardiol. 2010, 55, 1080-1090. [CrossRef] [PubMed]

2. Grube, E.; Schuler, G.; Buellesfeld, L.; Gerckens, U.; Linke, A.; Wenaweser, P.; Sauren, B.; Mohr, F.W.; Walther, T.; Zickmann, B.; et al. Percutaneous aortic valve replacement for severe aortic stenosis in high-risk patients using the second- and current third-generation self-expanding CoreValve prosthesis: Device success and 30-day clinical outcome. J. Am. Coll. Cardiol. 2007, 50, 69-76. [CrossRef] [PubMed]

3. Baan, J., Jr.; Yong, Z.Y.; Koch, K.T.; Henriques, J.P.; Bouma, B.J.; Vis, M.M.; Cocchieri, R.; Piek, J.J.; de Mol, B.A. Factors associated with cardiac conduction disorders and permanent pacemaker implantation after percutaneous aortic valve implantation with the CoreValve prosthesis. Am. Heart J. 2010, 159, 497-503. [CrossRef] [PubMed]

4. Chamandi, C.; Barbanti, M.; Munoz-Garcia, A.; Latib, A.; Nombela-Franco, L.; Gutiérrez-Ibanez, E.; Veiga-Fernandez, G.; Cheema, A.N.; Cruz-Gonzalez, I.; Serra, V.; et al. Long-Term Outcomes in Patients with New-Onset Persistent Left Bundle Branch Block Following TAVR. JACC Cardiovasc. Interv. 2019, 12, 1175-1184. [CrossRef]

5. Houthuizen, P.; Van Garsse, L.A.F.M.; Poels, T.T.; De Jaegere, P.; Van Der Boon, R.M.; Swinkels, B.M.; Berg, J.M.T.; Van Der Kley, F.; Schalij, M.J.; Baan, J.; et al. Left Bundle-Branch Block Induced by Transcatheter Aortic Valve Implantation Increases Risk of Death. Circulation 2012, 126, 720-728. [CrossRef]

6. Piazza, N.; Onuma, Y.; Jesserun, E.; Kint, P.P.; Maugenest, A.-M.; Anderson, R.H.; de Jaegere, P.P.T.; Serruys, P.W. Early and Persistent Intraventricular Conduction Abnormalities and Requirements for Pacemaking after Percutaneous Replacement of the Aortic Valve. JACC Cardiovasc. Interv. 2008, 1, 310-316. [CrossRef]

7. Roten, L.; Wenaweser, P.; Delacrétaz, E.; Hellige, G.; Stortecky, S.; Tanner, H.; Pilgrim, T.; Kadner, A.; Eberle, B.; Zwahlen, M.; et al. Incidence and Predictors of Atrioventricular Conduction Impairment after Transcatheter Aortic Valve Implantation. Am. J. Cardiol. 2010, 106, 1473-1480. [CrossRef]

8. Nuis, R.-J.; Van Mieghem, N.M.; Schultz, C.J.; Tzikas, A.; Van Der Boon, R.M.; Maugenest, A.-M.; Cheng, J.; Piazza, N.; Van Domburg, R.T.; Serruys, P.W.; et al. Timing and potential mechanisms of new conduction abnormalities during the implantation of the Medtronic CoreValve System in patients with aortic stenosis. Eur. Heart J. 2011, 32, 2067-2074. [CrossRef] [PubMed]

9. Schymik, G.; Tzamalis, P.; Bramlage, P.; Heimeshoff, M.; Würth, A.; Wondraschek, R.; Gonska, B.-D.; Posival, H.; Schmitt, C.; Schröfel, H.; et al. Clinical impact of a new left bundle branch block following TAVI implantation: 1-year results of the TAVIK cohort. Clin. Res. Cardiol. 2014, 104, 351-362. [CrossRef]

10. Ando, T.; Takagi, H.; ALICE (All-Literature Investigation of Cardiovascular Evidence) Group. The Prognostic Impact of NewOnset Persistent Left Bundle Branch Block Following Transcatheter Aortic Valve Implantation: A Meta-analysis. Clin. Cardiol. 2016, 39, 544-550. [CrossRef]

11. Poels, T.T.; Houthuizen, P.; Van Garsse, L.A.; Maessen, J.G.; de Jaegere, P.; Prinzen, F.W. Transcatheter aortic valve implantation-induced left bundle branch block: Causes and consequences. J. Cardiovasc. Transl. Res. 2014, 7, 395-405. [CrossRef] [PubMed]

12. Moreno, R.; Dobarro, D.; López de Sá, E.; Prieto, M.; Morales, C.; Calvo Orbe, L.; Moreno-Gomez, I.; Filgueiras, D.; SanchezRecalde, A.; Galeote, G.; et al. Cause of complete atrioventricular block after percutaneous aortic valve implantation: Insights from a necropsy study. Circulation 2009, 120, 29-30. [CrossRef] [PubMed] 
13. Strauss, D.G.; Selvester, R.H.; Wagner, G.S. Defining left bundle branch block in the era of cardiac resynchronization therapy. Am. J. Cardiol. 2011, 107, 927-934. [CrossRef] [PubMed]

14. Surawicz, B.; Childers, R.; Deal, B.J.; Gettes, L.S.; Bailey, J.J.; Gorgels, A.; Hancock, E.W.; Josephson, M.; Kligfield, P.; Kors, J.A.; et al. AHA/ACCF/HRS recommendations for the standardization and interpretation of the electrocardiogram: Part III: Intraventricular conduction disturbances: A scientific statement from the American Heart Associ-ation Electrocardiography and Arrhythmias Committee, Council on Clinical Cardiology; the American College of Cardiology Foundation; and the Heart Rhythm Society. Endorsed by the International Society for Computerized Electrocardiology. J. Am. Coll. Cardiol. 2009, 53, 976-981. [PubMed]

15. Poels, T.T.; Stassen, R.; Kats, S.; Veenstra, L.; van Ommen, V.; Kietselaer, B.; Houthuizen, P.; Maessen, J.G.; Prinzen, F.W. Effective Distance between Aortic Valve and Conduction System Is an Independent Predictor of Persistent Left Bundle Branch Block during Transcatheter Aortic Valve Implantation. Medicina 2021, 57, 476. [CrossRef]

16. Van der Boon, R.M.; Nuis, R.J.; Van Mieghem, N.M.; Jordaens, L.; Rodés-Cabau, J.; van Domburg, R.T.; Serruys, P.W.; Anderson, R.H.; de Jaegere, P.P. New conduction abnormalities after TAVI-frequency and causes. Nat. Rev. Cardiol. 2012, 9, 454-463. [CrossRef]

17. Nazif, T.M.; Williams, M.R.; Hahn, R.T.; Kapadia, S.; Babaliaros, V.; Rodés-Cabau, J.; Szeto, W.Y.; Jilaihawi, H.; Fearon, W.F.; Dvir, D.; et al. Clinical implications of new-onset left bundle branch block after transcatheter aortic valve replacement: Analysis of the PARTNER experience. Eur. Heart J. 2014, 35, 1599-1607. [CrossRef]

18. Narula, O.S. Longitudinal dissociation in the His bundle. Bundle branch block due to asynchronous conduction within the His bundle in man. Circulation 1977, 56, 996-1006. [CrossRef] [PubMed]

19. Lazzara, R.; Yeh, B.K.; Samet, P. Functional Transverse Interconnections within the His Bundle and the Bundle Branches. Circ. Res. 1973, 32, 509-515. [CrossRef] [PubMed]

20. Dhein, S. Cardiac Ischemia and Uncoupling: Gap Junctions in Ischemia and Infarction. Cardiovasc. Gap Junctions 2006, 42, 198-212. [CrossRef]

21. Cascio, W.E.; Yang, H.; Muller-Borer, B.J.; Johnson, T.A. Ischemia-induced arrhythmia: The role of connexins, gap junctions, and attendant changes in impulse propagation. J. Electrocardiol. 2005, 38, 55-59. [CrossRef] [PubMed]

22. Rohr, S. Role of gap junctions in the propagation of the cardiac action potential. Cardiovasc. Res. 2004, 62, 309-322. [CrossRef] [PubMed]

23. Hamdan, A.; Guetta, V.; Klempfner, R.; Konen, E.; Raanani, E.; Glikson, M.; Goitein, O.; Segev, A.; Barbash, I.; Fefer, P.; et al. Inverse Relationship between Membranous Septal Length and the Risk of Atrioventricular Block in Patients Undergoing Transcatheter Aortic Valve Implantation. JACC Cardiovasc. Interv. 2015, 8, 1218-1228. [CrossRef]

24. Kostopoulou, A.; Karyofillis, P.; Livanis, E.; Thomopoulou, S.; Stefopoulos, C.; Doudoumis, K.; Theodorakis, G.; Voudris, V.; Anna, K.; Panagiotis, K.; et al. Permanent pacing after transcatheter aortic valve implantation of a CoreValve prosthesis as determined by electrocardiographic and electrophysiological predictors: A single-centre experience. Europace 2015, 18, 131-137. [CrossRef]

25. Scheinman, M.M.; Peters, R.W.; Suave, M.J.; Desai, J.; Abbott, J.A.; Cogan, J.; Wohl, B.; Williams, K. Value of the H-Q interval in pa-tients with bundle branch block and the role of prophylactic permanent pacing. Am. J. Cardiol. 1982, 50, 1316-1322. [CrossRef]

26. Van der Boon, R.M.; Houthuizen, P.; Urena, M.; Poels, T.T.; van Mieghem, N.M.; Brueren, G.R.; Altintas, S.; Nuis, R.J.; Serruys, P.W.; van Garsse, L.A.; et al. Trends in the occurrence of new conduction abnormalities after transcatheter aortic valve implantation. Catheter. Cardiovasc. Interv. 2015, 85, E144-E152. [CrossRef]

27. Aktug, Ö.; Dohmen, G.; Brehmer, K.; Koos, R.; Altiok, E.; Deserno, V.; Herpertz, R.; Autschbach, R.; Marx, N.; Hoffmann, R. Incidence and predictors of left bundle branch block after transcatheter aortic valve implantation. Int. J. Cardiol. 2012, 160, 26-30. [CrossRef]

28. Gutiérrez, M.; Rodés-Cabau, J.; Bagur, R.; Doyle, D.; Delarochellière, R.; Bergeron, S.; Lemieux, J.; Villeneuve, J.; Côté, M.; Bertrand, O.F.; et al. Electrocardiographic changes and clinical outcomes after transapical aortic valve implantation. Am. Heart J. 2009, 158, 302-308. [CrossRef]

29. Guetta, V.; Goldenberg, G.; Segev, A.; Dvir, D.; Kornowski, R.; Finckelstein, A.; Hay, I.; Goldenberg, I.; Glikson, M. Predictors and Course of High-Degree Atrioventricular Block After Transcatheter Aortic Valve Implantation Using the CoreValve Revalving system. Am. J. Cardiol. 2011, 108, 1600-1605. [CrossRef] [PubMed]

30. Siontis, G.C.; Jüni, P.; Pilgrim, T.; Stortecky, S.; Büllesfeld, L.; Meier, B.; Wenaweser, P.; Windecker, S. Predictors of permanent pace-maker implantation in patients with severe aortic stenosis undergoing TAVR: A meta-analysis. J. Am. Coll. Cardiol. 2014, 64, 129-140. [CrossRef]

31. Qintar, M.; Li, Z.; Vemulapalli, S.; Chhatriwalla, A.K.; Baron, S.J.; Kosinski, A.S.; Saxon, J.T.; Spertus, J.A.; Cohen, D.J.; Arnold, S.V. Association of Smoking Status with Long-Term Mortality and Health Status After Transcatheter Aortic Valve Replacement: Insights from the Society of Thoracic Surgeons / American College of Cardiology Transcatheter Valve Therapy Registry. J. Am. Heart Assoc. 2019, 8, e011766. [CrossRef] [PubMed]

32. Agarwal, M.; Agrawal, S.; Garg, L.; Reed, G.L.; Khouzam, R.N.; Ibebuogu, U.N. Impact of smoking in patients undergoing transcatheter aortic valve replacement. Ann. Transl. Med. 2018, 6, 2. [CrossRef] [PubMed] 